\title{
ПРИКЛАДИ ЗАСТОСУВАННЯ МЕТОДУ БЕЗРИЗИКОВОГО ЕКВІВАЛЕНТУ ДО ОЦІНКИ ІНВЕСТИЦІЙНИХ ПРОЕКТІВ
}

\author{
EXAMPLES OF APPLICATION \\ OF THE CERTAINTY EQUIVALENT METHOD \\ TO THE INVESTMENT PROJECT EVALUATION
}

\author{
Пенцак Євген Ярославович, \\ кандидат фрізико-математичних наук, доцент, \\ Національний університет «Києво-Могилянська академія» \\ ORCID: https://orcid.org/0000-0002-6899-3454 \\ Саврук Гелена Миколаївна \\ кандидат економічних наук, доцент, \\ Національний університет «Києво-Могилянська академія» \\ ORCID: https://orcid.org/0000-0003-4952-9936 \\ Саврук Олександр Йосипович \\ кандидат економічних наук, доцент, \\ Національний університет «Києво-Могилянська академія» \\ ORCID: https://orcid.org/0000-0002-0342-2837
}

\section{Pentsak Yevhen, Savruk Gelena, Savruk Oleksandr National University of «Kyiv-Mohyla Academy»}

Кожна компанія вирішує проблему ефективного використання фрінансових ресурсів, аналізуючи інвестиційну привабливість різних альтернатив. Для цього інвестиційні аналітики часто використовують традиційні інвестиційні критерії, побудовані на принципах дисконтування майбутніх грошових потоків, враховуючи ризиковість відповідного напрямку бізнесу. Такі методи оцінки інвестиційних проектів добре себе зарекомендували у випадках, коли фрінансова система працює ефективно, коли фрінансовий ринок насичений різноманітними фрінансовими інструментами, що допомагають бізнесу ефективно управляти ризиками і при необхідності залучати боргове чи партнерське фрінансування. Проте в умовах високо ризикового середовища бізнесу, коли на фрінансовому ринку відсутній широкий спектр фрінансових посередників, коли фрінансовий ринок $€$ неповним, то потрібно враховувати при оцінці інвестиційних проектів ставлення інвестора до ризику, його фрінансовий стан та характеристики існуючого портореля його бізнесів. У таких випадках для оцінки ризикових інвестиційних проектів використовують метод безризикового еквіваленту. Безризиковий еквівалент вказує на максимальну суму, яку готовий інвестувати інвестор у даний інвестиційний проект з врахуванням його ставлення до ризику, що описується з допомогою його функції задоволення від грошей. Дана робота присвячена саме демонстрації на прикладах застосування методу безризикового еквіваленту для оцінки інвестиційних проектів, що описуються з допомогою дискретних і неперервних випадкових величин. У роботі показано, як з допомогою чисельних симулятивних методів можна знаходити безризиковий еквівалент інвестиційних проектів у припущенні високо ризикових інвестицій, що характеризуються довгими і товстими хвостами відповідних розподілів. Запропонований в роботі підхід дозволяє ефективно інтегрувати нову ринкову та експертну інформацію, і його можна використовувати до оцінки інноваційних напрямків бізнесу високотехнологічних компаній, чи до інвестиційних продуктів, в основі яких лежить їх здатність «добувати» криптовалюту, наприклад, біткоїн чи ефрір. Метод оцінки інвестиційної привабливості з допомогою безризикового еквіваленту допускає також можливість інтеграції з іншими інвестиційними методами, наприклад, методом реальних опціонів, а також дає можливість застосовувати аналіз чутливості до різних фракторів впливу і симулятивний аналіз Монте Карло.

Ключові слова: функція корисності, безризиковий еквівалент, оцінка інвестиційного проекту, дискретний розподіл, фуннкція щільності Пірсона четвертого типу, очікуване значення корисності.

Каждая компания решает проблему эфффективного использования фринансовых ресурсов, анализируя инвестиционную привлекательность различных альтернатив. Для этого инвестиционные аналитики часто ис- 
пользуют традиционные инвестиционные критерии, построенные на принципах дисконтирования будущих денежных потоков, учитывая рискованность соответствующего направления бизнеса. Такие методы оценки инвестиционных проектов хорошо себя зарекомендовали в случаях, когда фринансовая система работает эффрективно, когда фринансовый рынок насыщен разнообразными ффинансовыми инструментами, которые помогают бизнесу эфффективно управлять рисками и при необходимости привлекать долговое или партнерское фринансирование. Однако в условиях высоко рискованной среды бизнеса, когда на фринансовом рынке отсутствует широкий спектр финансовых посредников, когда фринансовый рынок является неполным, то нужно учитывать при оценке инвестиционных проектов отношение инвестора к риску, его фринансовое состояние и характеристики существующего портфеля его бизнесов. В таких случаях для оценки рисковых инвестиционных проектов используют метод безрискового эквивалента. Безрисковый эквивалент указывает на максимальную сумму, которую готов инвестировать инвестор в данный инвестиционный проект с учетом его отношение к риску, что описывается с помощью его функции удовольствие от денег. Данная работа посвящена именно демонстрации на примерах применения метода безрискового эквивалента для оценки инвестиционных проектов, которые описываются с помощью дискретных и непрерывных случайных величин. В работе показано, как с помощью численных симулятивных методов можно находить безрисковый эквивалент инвестиционных проектов в предположении высоко рисковых инвестиций, характеризующихся длинными и толстыми хвостами соответствующих распределений. Предложенный в работе подход позволяет эффективно интегрировать новую рыночную и экспертную информацию, и его можно использовать к оценке инновационных направлений бизнеса высокотехнологичных компаний, или к инвестиционным продуктам, в основе которых лежит их способность «добывать» криптовалюту, например, биткоин или эфир. Метод оценки инвестиционной привлекательности с помощью безрискового эквивалента допускает также возможность интеграции с другими инвестиционными методами, например, методом реальных опционов, а также дает возможность применять анализ чувствительности к различным фракторам влияния и симуляционный анализ Монте Карло.

Ключевые слова: функция полезности, безрисковый эквивалент, оценка инвестиционного проекта, дискретное распределение, фрункция плотности Пирсона четвертого типа, ожидаемое значение полезности.

Each company solves the problem of efficient use of financial resources by analyzing the investment attractiveness of various alternatives. For this, investment analysts often use traditional investment criteria, built on the principles of discounting future cash flows, given the riskiness of the relevant business line. Such methods of evaluating investment projects have proven themselves in cases where the financial system works efficiently, when the financial market is saturated with a variety of financial instruments that help businesses effectively manage risks and, if necessary, attract debt or partner financing. However, in a highly risky business environment, when there is no wide range of financial intermediaries in the financial market, when the financial market is incomplete, it is necessary to take into account the investor's attitude to risk, its financial condition and the characteristics of the existing portfolio of its businesses when evaluating investment projects. In such cases, the certainty equivalent method is used to evaluate risky investment projects. The certainty equivalent indicates the maximum amount that an investor is ready to invest in a given investment project, taking into account his attitude to risk, which is described with the help of his utility function of money. This work is devoted specifically to the demonstration of the application of the certainty equivalent method for evaluating investment projects, which are described using discrete and continuous random variables. The paper shows how, using numerical simulation methods, it is possible to find the certainty equivalent of investment projects under the assumption of high-risk investments, characterized by long and thick tails of the corresponding distributions. The proposed approach allows to integrate effectively new market and expert information, and it can be used to assess innovative business areas of high-tech companies, or to price investment products based on their ability to "mine" cryptocurrencies, such as bitcoin or ether. The method of assessing investment attractiveness using a certainty equivalent also allows the possibility of its integration with other investment methods, for example, the method of real options, and also makes it possible to apply sensitivity analysis to various influencing factors and Monte Carlo simulation analysis.

Keywords: utility function, certainty equivalent, investment project valuation, discrete distribution, Pearson's density function of fourth-type, expected utility value.

Постановка проблеми. Проблема оцінки інвестиційної привабливості бізнес-проектів має практичний інтерес не тільки серед інвесторів, але й у середовищі фрінансових посередників та в академічних колах. Що більш розвиненою $€$ фрінансова система країни, в якій присутніми $€$ орінансово-аналітичні компанії, біржі, інвестиційні компанії, наявний широкий спектр похідних фрінансових інструментів та страхових продуктів, то ми можемо використовувати такі стандартні методи оцінювання інвестиційних проектів, як метод дисконтова- них грошових потоків (ДГП) чи метод реальних опціонів (РО). Проте виникають серйозні труднощі $з$ інвестиційною оцінкою проектів, коли фрінансово-економічна система не $€$ достатньо розвиненою, коли бізнес-середовище $€$ сильно ризиковим, коли на фрінансовий результат впливають погодні умови, розподіл впливу політичних сил у країні, міграційна динаміка, можливість загострення військових дій тощо. I саме вивчення проблеми оцінки інвестиційних проектів у турбулентному середовищі бізнесу і досліджується в даній роботі. 
Аналіз останніх досліджень. У випадках, коли фрінансова система країни не $є$ розвиненою, використовують підхід до оцінки інвестиційних проектів з використанням безризикового еквіваленту, БЕ, (СE, certainty equivalent), що обчислюється на основі фрункції корисності фоон Неймана-Моргенштерна [1]. Ця проблема вивчалась, зокрема, в роботах [2; 3]. В основному у літературі розглядаються дискретні випадкові змінні, що описують результати інвестування, на основі яких обчислюється значення безризикового еквіваленту від інвестування для інвестора з заданою фрункцією задоволення Бернуллі від грошей. У класичній літературі з фрінансового та інвестиційного менеджменту також аналізується підхід визначення значення БЕ для інвестиційних проектів, які визначаються неперервними одновимірними фрункціями розподілу.

У фрінансово-економічній літературі присутній широкий пласт робіт з оцінки інвестиційних проектів 3 використанням моделей індиферентного ціноутворення (indifference pricing) [4-9]. У цих роботах розглядаються підходи до врахування неринкових ризиків у поєднанні 3 ринковими шляхом використання міри ентропії та нейтральних до ризику ймовірностей.

Проте інвестиційні аналітики потребують практичних прийомів оцінки вартості проектів у ризиковому середовищі за умови відсутності розвиненої фрінансової системи, зокрема за відсутності високо ліквідних біржових інструментів.

Методика досліджень. Метою даної роботи $€$ дослідження практичних аспектів оцінювання високо ризикових інвестиційних проектів методом знаходження безризикового еквіваленту з використанням чисельного моделювання. Основною методикою знаходження оцінки безризикового еквіваленту $\epsilon$ чисельний метод обчислення значень інтегралів з допомогою симуляцій Монте Карло.

Формулювання цілей статті (постановка завдання). Проблема чисельного застосування оцінки інвестиційної привабливості інвестиційного проекту у дуже ризиковому середовищі за умов відсутності розвиненого фрінансового та страхового ринків потребує використання неперервних срункцій розподілу багатовимірних випадкових величин, що описують ризики притаманні даному інвестиційному середовищу та конкретному інвестиційному проекту. Саме практичне застосування методики оцінки інвестиційних проектів 3 допомогою безризикового еквіваленту на простих прикладах і розглядається у даній статті. Саме практичне застосування мето- дики оцінки інвестиційного проекту у ризиковому середовищі часто залишається відкритим. Як впливає фрінансовий стан інвестора на оцінку інвестиційної привабливості? Як на цю оцінку впливають характеристики бізнес-середовища, специфічні ризики проекту та ставлення інвестора до ризику? Як на оцінку інвестицій впливає наявність та доступність інформації? Як знайти інтервал оцінювання інвестиційного проекту при його купівлі чи продажу? У даній роботі даються відповіді на деякі з цих запитань.

Виклад основного матеріалу дослідження. У даній роботі ми обмежимось найпростішим класом фрункцій, які описують задоволення інвестора від багатства, а саме розглянемо клас фрункцій

$$
u(w ; \gamma)=\frac{w^{\gamma}}{\gamma},
$$

де $\gamma \in(0 ; 1)$ - параметр, який характеризує ставлення інвестора до ризику. Можна переконатись прямою перевіркою, що всі фрункції, що описуються фрормулою (1) $є$ зростаючими та опуклими вгору, тобто для них виконується властивість $u^{\prime}(w ; \gamma)>0$ та $u^{\prime \prime}(w ; \gamma)<0$ для всіх значень $W>0$ та всіх значень $\gamma \in(0 ; 1)$.

Оскільки поняття ризику $є$ одним 3 фрундаментальних понять у сучасній фрінансовій економіці, то для його аналізу виникла потреба розширити поняття функції корисності від грошей на простір лотерей (lottery space). Припустимо, що інвестор вибирає серед лотерей, що характеризуються вектором виплат $x=\left(x_{1}, x_{2}, \ldots, x_{N}\right)$ відповідно до ймовірностей $p=\left(p_{1}, p_{2}, \ldots, p_{N}\right)$. Лотерею ми позначатимемо символом $L(x ; p)$. Для оцінки ризикових альтернатив у фрінансовій економіці прийнято використовувати фрункцію корисності фон Неймана-Моргенштерна

$$
U(L(x ; p))=E[u(L(x ; p))]=\sum_{i=0}^{N} p_{i} \times u\left(x_{i}, \gamma\right)
$$

Якщо ж лотерея визначається фрункцією щільності $f(x ; \alpha)$ неперервно розподіленої випадкової величини $X$, то використовують інтегральний аналог фрормули (2):

$$
U(X)=E[u(X)]=\int_{0} u(x ; \gamma) \times f(x ; \alpha) d x
$$

Розглянемо для прикладу фрункцію щільності логнормального розподілу

$$
f_{L N}(x ; \mu, \sigma)=\frac{1}{2 x \sqrt{\pi} \sigma} \exp \left(-\frac{(\ln (x)-\mu)^{2}}{2 \sigma^{2}}\right),
$$

де $\mu \in(-\infty ;+\infty), \sigma \in(0 ;+\infty)$. Застосувавши до випадкової величини, що описується фрункцією щільності (4) фрункцію очікуваної корисності (2) 3 фрункцією задоволення інвестора від багатства (1), ми отримаємо 


$$
E[u(x)]=\int_{0}^{+\infty} \frac{x^{\gamma}}{\gamma} \times f_{L N}(x ; \mu, \sigma) d x=\int_{-\infty}^{+\infty} \exp (\gamma \times y) \times \exp \left(-\frac{(y-\mu)^{2}}{2 \sigma^{2}}\right) d y=\frac{1}{\gamma} \times \exp \left(\gamma \times \mu+\frac{1}{2} \times \gamma^{2} \times \sigma^{2}\right)
$$

На цьому прикладі ми бачимо взаємозв'язок між концепцією оцінки ризикових альтернатив 3 допомогою функції очікуваної корисності та фрункцією корисності, визначеної на основі описових характеристик випадкової величини.

Безризиковим еквівалентом для інвестора 3 фрункцією задоволення від багатства $u(w)$ при купівлі інвестиційного проекту $X$, що описується лотереєю $L(x ; \pi)$, називається величина $C E_{B}$, що визначається рівністю:

$$
u\left(w_{0}\right)=\sum_{i=0}^{N} p_{i} \times u\left(w_{0}-C E_{B}+x_{i}\right)
$$

Приклад 1. Розглянемо економічного агента з початковим рівнем багатства $w_{0}=10$ і фрункцією задоволення від багатства (1) 3 параметром $\gamma=\frac{1}{2}$, тобто $u(w)=2 \sqrt{w}$. Нехай лотерея $L=\left(G, B ; p_{G}, p_{B}\right) \in$ бінарною зі значеннями $G=5, B=1, p_{G} \in[0.6,0.7] \mathrm{i}$, відповідно $p_{B}=1-p_{G}$. Припустимо, що інвестор збирається інвестувати в проект, що описується лотереєю $L$. Знайдемо безризиковий еквівалент цього проекту $C E_{B}^{p_{G}}$ для інвестора у припущенні, що $p_{G} \in[0.6,0.7]$.

$$
2 \sqrt{w_{0}}=2 \times\left(p_{G} \times \sqrt{w_{0}-C E_{B}^{p_{G}}+G}+\left(1-p_{G}\right) \times \sqrt{w_{0}-C E_{B}^{p_{G}}+B}\right)
$$

Підставивши у (7) значення $w_{0}=10, G=5$, $B=1$, ми отримаємо для $p_{G}=0.6$ значення $C E_{B}^{p_{G}=0.6}=3.30$, а для $p_{G}=0.7-$ значення $C E_{B}^{p_{G}=0.7}=3.71$. Отже, якщо $p_{G} \in[0.6,0.7]$, то безризиковий еквівалент $C E_{B}^{p_{G}} \in[3.30 ; 3.71]$. Зауважимо, що при цьому очікуване значення виплат $E(L)$ по проекту, що описується лотереєю $L$, буде $E(L) \in[3.4 ; 3.8]$. Зрозуміло, що завжди $C E_{B}^{p_{G}}<E\left(G, B ; p_{G}, p_{B}\right)$, оскільки інвестор вимагає компенсації за ризик інвестиційного проекту у вигляді так званої «премії за ризик».

Припустимо, що економічний агент вирішує здобути детальнішу інфрормацію стосовно виплат по інвестиційному проекту, що описується $з$ допомогою лотереї $L=\left(G, B ; p_{G}, p_{B}\right)$. Ця додаткова інформація відобразиться у записі інвестиційного проекту 3 допомогою лотереї $L^{\prime}=\left(l_{1}, I_{2}, I_{3}, I_{4}, I_{5} ; p_{1}, p_{2}, p_{3}, p_{4}, p_{5}\right)$, що також вплине на оцінку безризикового еквіваленту інвестиційного проекту.

Приклад 2. Розглянемо економічного агента $з$ початковим рівнем багатства $w_{0}=10$ і фрункцією задоволення від багатства (1) 3 параметром $\gamma=\frac{1}{2}$. Знайдемо безризиковий еквівалент $C E_{B}$ інвестиційного проекту, що описується 3 допомогою лотереї $L^{1}=(6,5,4,2,1 ; 0.1,0.3,0.3,0.2,0.1) . \quad$ Розв'язавши рівняння (6) для заданої фуункції $u(w ; \gamma)=\frac{w^{\gamma}}{\gamma}$ 3 параметром $\gamma=\frac{1}{2}, w_{0}=10$ та лотереєю $L^{1}$, ми отримаємо $C E_{B}^{1}=3.74$. А для лотеpeї $L^{2}=(6,5,4,2,1 ; 0.1,0.2,0.3,0.2,0.2)$ значення $C E_{B}^{2}=3.33$. Зауважимо, що для лотерей $L^{1}$ та $L^{2}: E\left(L^{1}\right)=3.8, \operatorname{std}\left(L^{1}\right)=1.54, E\left(L^{2}\right)=3.4$, $s t d\left(L^{2}\right)=1.68$. Які і Прикладі 1 тут виконуються нерівності $C E_{B}^{1}<E\left(L^{1}\right)$ та $C E_{B}^{2}<E\left(L^{2}\right)$, оскільки інвестор вимагає премії за ризик, що може бути виміряний, наприклад, значеннями стандартного відхилення $s t d\left(L^{1}\right)$ та $s t d\left(L^{2}\right)$. Якщо ж інвестор не впевнений стосовно розподілу ймовірностей виплат по інвестиційному проекту $I=\left(I_{1}, I_{2}, I_{3}, I_{4}, I_{5}\right)$, але припускає, що можливі лотереї $L=\left(6,5,4,2,1 ; p_{1}, p_{2}, p_{3}, p_{4}, p_{5}\right)$ задовольняють співвідношення $F\left(L^{1}\right) \leq F(L) \leq F\left(L^{2}\right)$, де $F$ - відповідні фрункції розподілу, що визначаються лотереями $L^{1}$ та $L^{2}$, то можна показати, що $C E_{B}(L) \in\left[C E_{B}\left(L^{2}\right) ; C E_{B}\left(L^{1}\right)\right]=[3.33 ; 3.74]$.

Приклад 3. Розглянемо економічного агента 3 початковим рівнем багатства $w_{0}=10$ і фрункцією задоволення від багатства (1) з параметром $\gamma=\frac{1}{2}$. Знайдемо безризиковий еквівалент $C E_{B}$ інвестиційного проекту, що описується 3 допомогою неперервної нормально розподіленої випадкової величини

$$
f_{N}(x ; \mu, \sigma)=\frac{1}{2 \sqrt{\pi} \sigma} \exp \left(-\frac{(x-\mu)^{2}}{2 \sigma^{2}}\right)
$$

з параметрами $\mu$ та $\sigma$.У цьому випадку $C E_{B}(\mu, \sigma)$ аналогічно до срормули (6) ми можемо знайти з рівняння

$$
\frac{w_{0}^{\gamma}}{\gamma}=E\left[u\left(w_{0}-C E_{B}(\mu, \sigma)+x\right)\right]=\int_{-\infty}^{+\infty} \frac{\left(w_{0}-C E_{B}(\mu, \sigma)+x\right)^{\gamma}}{\gamma} \times f_{N}(x ; \mu, \sigma) d x
$$

Використовуючи чисельні методи інтегрування, можнапоказати, що $C E_{B}(3.4,1.68)=3.33$ та $C E_{B}(3.8,1.54)=3.74$.
Приклад 4. Розглянемо економічного агента 3 початковим рівнем багатства $w_{0}=10$ і фрункцією задоволення від багатства (1) 3 параме- 
тром $\gamma=\frac{1}{2}$. Знайдемо безризиковий еквівалент $C E_{B}$ інвестиційного проекту, що описується 3 допомогою неперервної логнормально розподіленої випадкової величини (4) 3 параметрами $\mu_{1}$ та $\sigma_{1}$, які визначаються 3 умов

$$
\begin{gathered}
\int_{0}^{+\infty} x \times f_{L N}\left(x ; \mu_{1}, \sigma_{1}\right) d x=\mu \\
\int_{0}^{+\infty}(x-\mu)^{2} \times f_{L N}\left(x ; \mu_{1}, \sigma_{1}\right) d x=\sigma^{2}
\end{gathered}
$$

Відомо, що $\mu_{1}$ та $\sigma_{1}$, які $є$ розв'язками системи (10)-(11) допускають аналітичне представлення:

$$
\begin{gathered}
\mu_{1}=\ln \left(\frac{\mu^{2}}{\sqrt{\frac{\sigma^{2}}{\mu^{2}}+1}}\right) \\
\sigma_{1}=\sqrt{\ln \left(\frac{\sigma^{2}}{\mu^{2}}+1\right)}
\end{gathered}
$$

Тоді для значень $\mu=3.4, \sigma=1.68$ ми за фрормулами (12)-(13) знайдемо значення параметрів $\mu_{1}=1.1145, \sigma_{1}=0.2185, \mathrm{i}$, для значень $\mu=3.4$, $\sigma=1.68$ - відповідно, значення параметрів $\mu_{1}=1.2590, \sigma_{1}=0.1521$ логнормального розподілу. Значення $C E_{B}\left(\mu_{1}, \sigma_{1}\right)$ можемо знайти з рівняння

$$
\frac{w_{0}^{\gamma}}{\gamma}=E\left[u\left(w_{0}-C E_{B}(\mu, \sigma)+X\right)\right]=\int_{-\infty}^{+\infty} \frac{\left(w_{0}-C E_{B}\left(\mu_{1}, \sigma_{1}\right)+x\right)^{\gamma}}{\gamma} \times f_{L N}\left(x ; \mu_{1}, \sigma_{1}\right) d x
$$

Використовуючи чисельні методи інтегрування, знайдемо значення $C E_{B}(3.4,1.68)=3.112 \quad$ i $\quad C E_{B}(3 \cdot 8,1.54)=3.555$. Отже, у припущенні логнормальності розподілу результатів інвестування 3 заданими середніми значеннями та стандартними відхиленнями ми отримаємо, що $C E_{B} \in\left[C E_{B}(3.4,1.68) ; C E_{B}(3.8,1.54)\right]=[3.112 ; 3.555]$. Виходить, що форма розподілу випадкової величини, що описує інвестиційний проект, суттєво впливає на оцінку інвестицій з допомогою методології безризикового еквіваленту.

Загальновідомо, що вибірки значень багатьох фрінансових показників результатів діяль- ності компаній, чи майбутні значення прибутків та грошових потоків від інвестування не можна описати не тільки 3 допомогою нормального, але й 3 допомогою широко вживаних у літературі гамма та логнормального розподілів. у таких випадках у ризик-менеджменті використовують розподіли, які володіють довгими та товстими хвостами, тобто допускають великі втрати та 3 достатньо високою ймовірністю. Зокрема, у фрінансах, ризик менеджменті, страховому менеджменті особливої популярності набув розподіл Пірсона четвертого типу.

Функцію щільності розподілу Пірсона четвертого типу (PTIV) можна записати у вигляді

$$
f_{P T I V}(x ; \mu, \alpha, \delta, \rho)=k\left[\left(\frac{x-\mu-\alpha}{\delta}\right)^{2}+1\right]^{-\frac{1}{2}(\rho+2)} \exp \left[-\frac{\alpha \rho}{\delta} \operatorname{arctg}\left(\frac{x-\mu-\alpha}{\delta}\right)\right]
$$

де - нормуючий множник, а математичне сподівання $\mu$ та варіація $\sigma^{2}$, відповідно, дорівнюють $\mu$ та

$$
\sigma^{2}=\frac{\alpha^{2}+\delta^{2}}{\rho-1}
$$

Приклад 5. Розглянемо економічного агента з початковим рівнем багатства $w_{0}=10$ і фрункцією задоволення від багатства (1) 3 параметром $\gamma=\frac{1}{2}$. Знайдемо безризиковий еквівалент $C E_{B}^{2}$ інвестиційного проекту, що описується неперервно розподіленою випадковою величиною 3 функцією щільності Пірсона четвертого типу (15). Припустимо, що у фрормулі (15) $\mu=3.4, \alpha=3, \rho=5$ і $\delta=1.513$. Тоді 3 фрормули (16) знайдемо $\sigma=\sqrt{\frac{\alpha^{2}+\delta^{2}}{\rho-1}}=1.68$. Зобразимо графрічно фрункцію щільності (15) з заданими параметрами і порівняємо ії̈ з фрункцією щільності нормального розподілу (8) зі значеннями $\mu=3.4$ і $\sigma=1.68$.

3 рис. 1 ми бачимо, що хвіст фуункції щільності розподілу PTIV є довшим та товстішим у порівнянні з функцією щільності нормального розподілу випадкової величини з однаковими описовими характеристиками середнього значення та стандартного відхилення. Значення $C E_{B}(\mu, \alpha, \delta, \rho)$ можемо знайти з рівняння

$$
\frac{W_{0}^{\gamma}}{\gamma}=\int_{-\infty}^{+\infty} \frac{\left(w_{0}-C E_{B}(\mu, \alpha, \delta, \rho)+x\right)^{\gamma}}{\gamma} \times f_{P T I V}(x ; \mu, \alpha, \delta, \rho) d x
$$




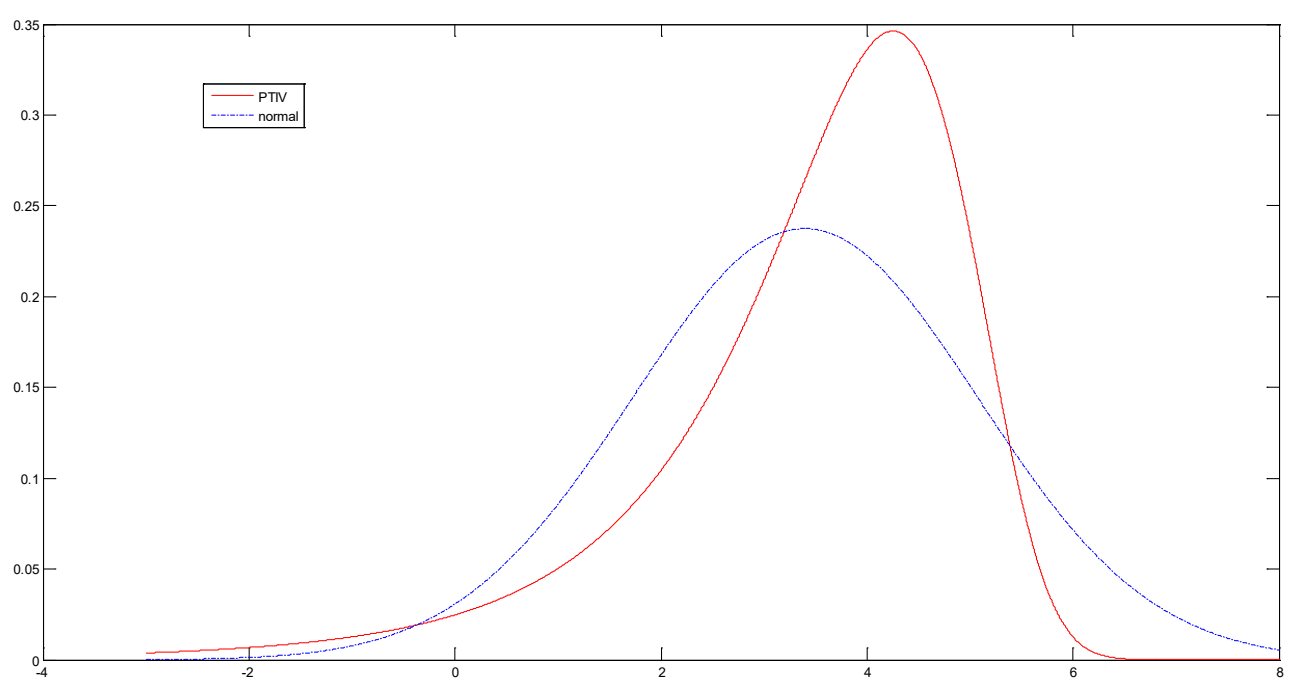

Рис. 1. Функції щільності нормально розподіленої випадкової величини з параметрами $\mu=3.4 \mathrm{i} \sigma=1.68$ та розподілу PTIV з параметрами

$$
\mu=3.4, \alpha=3, \rho=5 \text { i } \delta=1.513
$$

У випадку $\mu=3.4, \alpha=3, \rho=5$ і $\delta=1.513$ ми отримаємо $C E_{B}(3.4,3,5,1.513)=3.07$. Для випадку $\mu=3.8, \alpha=3, \rho=5$ і $\delta=0.6974$ значення $C E_{B}(3.8,3,5,0.6974)=3.45$. Загалом, уприпущенні розподілу Пірсона четвертого типу ми отримаємо, що $C E_{B} \in\left[C E_{B}(3.4,3,5,1.513)\right.$; $\left.C E_{B}(3.8,3,5,0.6974)\right]=[3.07 ; 3.45]$.

Отже, ми приходимо до висновку, що метод оцінки інвестиційного проекту з допомогою безризикового еквіваленту адекватно враховує ризики проекту та бізнес-середовища, зменшуючи критичну суму $C E_{B}$, яку інвестор готовий інвестувати у даний проект. У цілому усі оцінки значення безризикового еквіваленту, які розглядались у прикладах 1-5 виявились досить узгодженими. Що більше інфрормації ми враховували в розподілі виплат за результатами інвестування, то оцінка безризикового еквіваленту зменшувалась та відповідний коридор оцінок звужувався.

У ризиковому середовищі, в якому відсутній широкий спектр фрінансових інструментів та фрінансових посередників, коли не можемо використовувати метод нейтральних до ризику ймовірностей та метод індиферентного ціноутворення, то для оцінки інвестиційних проектів можна використовувати метод безризикового еквіваленту.

Висновки. У роботі продемонстровано на прикладах методику обчислення безризикового еквіваленту ризикових інвестиційних проектів, які задаються 3 допомогою дис- кретних та неперервних випадкових величин. Запропонований підхід можна застосовувати у бізнес-середовищі, в якому відсутня повноцінна орінансова система, ліквідна біржа цінних паперів, відсутні похідні фрінансові інструменти тощо.

Особливої популярності набувають інвестиційні продукти, що ґрунтуються на здатності «добувати» різноманітні криптовалюти з використанням певної обчислювальної потужності протягом деякого періоду часу. У випадках, коли дослідникам важко описати природу руху базового продукту у вигляді стохастичного процесу, або коли доводиться робити оцінки у середовищі з високою волатильністю, то тоді рекомендовано застосувати запропоновану вище методику.

Підхід до інвестиційної оцінки ризикових проектів 3 допомогою безризикового еквіваленту увійшов у класичну літературу 3 фрінансового менеджменту, але не отримав свого широкого практичного застосовування через обчислювальну складність. У роботі було показано, що звичайні обчислювальні потужності і базове програмне забезпечення дозволяють досить швидко здійснювати всі інвестиційні оцінки, спираючись на метод безризикового еквіваленту.

У подальших дослідженнях планується показати можливість використання показника безризикового еквіваленту для інвестиційних проектів з багатофракторними джерелами ризику. 


\section{СПИСОК ВИКОРИСТАНИХ ДЖЕРЕЛ:}

1. Von Neumann J., Morgenstern O. Theory of Games and Economic Behavior, Princeton University Press, Princeton. 1944.

2. Wilson R. Auctions of Shares, The Quarterly Journal of Economics, 1979, 93(4), pp. 675-689.

3. McCord M., Neufville R. "Lottery Equivalents": Reduction of the Certainty Effect Problem in Utility Assessment, Management Science, 1986, 32(1), pp. 56-60.

4. Zariphopoulou T. A solution approach to valuation with unhedgeable risks. Finance Stochast, 2001, 5, pp. 61-82.

5. Musiela M., Sokolova E., Zariphopoulou T. Indifference valuation in incomplete binomial models. Mathematics In Action 3.2, 2010, pp. 1-36.

6. Frittelli M. The minimal entropy martingale measure and the valuation problem in incomplete markets, Mathematical Finance, 2000, 10, pp. 39-52.

7. Henderson V. Utility indifference pricing - An overview, Indifference Pricing: Theory and Applications, R. Carmona (ed.), Princeton University Press, 2009, pp. 44-72.

8. Musiela M., Zariphopoulou T. An example of indifference prices under exponential preferences, Finance and Stochastics, 2004, 8, pp. 229-239.

9. Musiela M., Zariphopoulou T. A valuation algorithm for indifference pricing in incomplete markets, Finance and Stochastics, 2004, 8, p. 339-414.

\section{REFERENCES:}

1. Von Neumann J., Morgenstern O. (1944). Theory of Games and Economic Behavior, Princeton University Press, Princeton.

2. Wilson R. (1979). Auctions of Shares, The Quarterly Journal of Economics, 93(4), pp. 675-689.

3. McCord M., Neufville R. (1986). "Lottery Equivalents": Reduction of the Certainty Effect Problem in Utility Assessment, Management Science, 32(1), pp. 56-60.

4. Zariphopoulou T. (2001). A solution approach to valuation with unhedgeable risks. Finance Stochast, 5 , pp. 61-82.

5. Musiela M., Sokolova E., Zariphopoulou T. (2010). Indifference valuation in incomplete binomial models. Mathematics In Action 3.2, pp. 1-36.

6. Frittelli M. (2000). The minimal entropy martingale measure and the valuation problem in incomplete markets, Mathematical Finance, 10, pp. 39-52.

7. Henderson V. (2009). Utility indifference pricing - An overview, Indifference Pricing: Theory and Applications, R. Carmona (ed.), Princeton University Press, pp. 44-72.

8. Musiela M., Zariphopoulou T. (2004). An example of indifference prices under exponential preferences, Finance and Stochastics, 8, pp. 229-239.

9. Musiela M., Zariphopoulou T. (2004). A valuation algorithm for indifference pricing in incomplete markets, Finance and Stochastics, 8, pp. 339-414. 